\title{
Didáctica de la poesía: estudio y propuestas metodológicas para la explotación de textos poéticos en el aula de E/LE
}

Recibido: febrero 2011

\author{
Enrique SANTAMARÍA BUSTO \\ New York University \\ enrique.santamaria@nyu.edu
}

Aceptado: marzo 2012

\begin{abstract}
RESUMEN
En los últimos años la revalorización de los textos poéticos en el aula de E/LE ha determinado una convivencia de consideraciones teóricas y procedimientos didácticos muy diferentes a la hora de valorar el uso y la explotación de este tipo de textos en clase. Hoy en día, la situación en el aula sigue pasando del rechazo total o matizado a la reivindicación absoluta, en cuyo último caso se ofrecen soluciones didácticas que en la mayoría de las ocasiones no tienen en cuenta sus posibilidades de tratamiento en el aula. El presente artículo intenta analizar las causas, para posteriormente aportar vías de acercamiento y explotación metodológicas que configuren un marco de actuación en la clase de Español como Lengua Extranjera.
\end{abstract}

Palabras clave: poesía, literatura, didáctica, explotación, metodología, E/LE

Teaching of poetry: review and methodological proposals for the exploitation of poetic texts in the classroom of Spanish as a Foreign Language

\begin{abstract}
In recent years the revaluation of the use and exploitation of poetic texts in the classroom of Spanish as a Foreign Language has determined a complex coexistence of theoretical considerations and didactic procedures. Today, the utilization of literature in the context of foreign language classroom continues to pass from the total or partial refusal to an absolute reclamation. When that is the case, it is common to see how didactic solutions are offered systematically without really considering proper exploitation techniques based both on the type of students that have Spanish as a Foreign Language, and the qualities and potential of the texts themselves. The present article tries to analyze the causes, and subsequently provide ways of approach and methodological exploitation that configure a framework of action in the class of Spanish as a Foreign Language.
\end{abstract}

Key words: poetry, literature, didactics, exploitation, methodology, Spanish as a Foreign Language 


\title{
L'enseignement de la poésie: Révision et considérations méthodologiques pour l'exploitation de textes poétiques en classe d'Espagnol Langue Étrangère
}

\begin{abstract}
RÉSUMÉ
Lorsque l'on tente d'apprécier l'usage et l'exploitation des textes poétiques en cours de $\mathrm{E} / \mathrm{LE}$, on remarque que, ces dernières années, la revalorisation de ces types de textes a supposé la coexistence de considérations esthétiques et de procédés didactiques très divers. Encore aujourd'hui, en cours, on passe d'un rejet total ou relatif, à une revendication absolue, auquel cas, la plupart du temps, les solutions didactiques mises en œuvre ne tiennent pas compte des possibilités de traitement en cours. Dans cet article, on tentera d'en analyser les causes pour ensuite apporter des pistes quant à l'approche et à l'exploitation méthodologiques qui pourraient constituer un cadre d'action en cours d'Espagnol comme Langue Étrangère.
\end{abstract}

Mots-clé: poésie, littérature, didactique, exploitation, méthodologie, E/LE

SUMARIO: 1. Introducción. 2. La poesía en el aula de LE. 2.1. Hacia la praxis. 3. Propuestas metodológicas. 3.1. Selección (I. Criterios lingüísticos y literarios, II. Criterios didácticos, III. Criterios temáticos). 3.2. Explotación: I. Actividades de prelectura: -a) Actividades de Predicción -b) Actividades de Contextualización). II. Actividades durante la lectura. III. Actividades posteriores a la lectura: -a) Actividades de Expansión -b) Actividades de Transformación -c) Actividades de Relación -d) Actividades de Reducción e) Actividades de Sustitución -f) Actividades de Debate). 4. Conclusión. 5. Selección bibliográfica. 6. ANEXO.

\section{INTRODUCCIÓN}

Como sabemos, la relación entre literatura y lengua en las enseñanzas de idiomas ha resultado casi siempre polémica. Hemos pasado de la enseñanza de la lengua a través de la literatura a la exclusión absoluta de ésta, y el movimiento pendular nos ha llevado a una reconsideración del papel que desempeña, o puede desempeñar, el fenómeno literario en una enseñanza de lenguas extranjeras. Este cambio en los postulados teóricos se vio pronto reflejado en el campo de E/LE a través de una implantación gradual de actividades orientadas a la explotación de textos literarios, especialmente poéticos. La literatura comenzó a estar cada vez más de moda hasta llegar a convertirse en un producto cultural perfecto: una simbiosis de lengua y cultura, de arte lingüístico, que las editoriales y los profesores empezaron a recoger, haciéndose eco.

Actualmente, el análisis de estas actividades muestra una gran variedad de explotaciones con propuestas dispares, aunque no siempre igual de eficaces. El estudio de esta cuestión revela que la implantación de la literatura en el aula de E/LE se encuentra con dos graves problemas: por un lado la ausencia de criterios específicos de explotación pedagógica en función de las características de un 
alumno que tiene el español como lengua extranjera. No se trata en este caso de llevar textos a clase -tras una elección adecuada-, sino de saber trabajarlos, sirviéndonos de la potencialidad que llevan dentro y de técnicas para estimularla, como podrá verse más adelante.

La segunda cuestión, más importante si cabe, se orienta al rechazo que la propia naturaleza del texto genera en profesores y alumnos. De nada sirve tener una buena planificación del poema si no nos gusta o no creemos en ello. Por esta razón, conocer las posibilidades del texto y desterrar viejos prejuicios académicos anclados en tradiciones dogmáticas procedentes, en la mayoría de los casos, de nuestros estudios en lengua materna, son fundamentales para comenzar a trabajar en ellos como lengua extranjera.

Hoy en día la situación de la poesía en el aula de E/LE demuestra que muchos profesores defienden la utilización de este tipo de textos en clase, pero pocas veces lo hacen. La explicación suele ser la falta de tiempo o la densidad del programa, que no permite introducir textos de este tipo al haber otros aspectos que cubrir "más importantes". En cambio, en otras ocasiones, cuando sí se hace, los textos suelen utilizarse para rellenar tiempo, completando, por ejemplo, los 10 últimos minutos de una clase. Sin ocultar los beneficios de acabar y de empezar la clase con un poema o un pequeño texto literario -lo cual no determina una necesidad cuantitativa a la hora de trabajar este tipo de textos- la realidad es que el uso de la literatura como recurso ocasional y simple y no como herramienta compleja y potente es una práctica frecuente en las aulas de E/LE.

Una de las razones más importantes es la frecuente disociación que se hace entre lengua y literatura en la práctica docente (Prado Aragonés, 2004: 329). Actuamos en numerosas ocasiones como nuestros manuales de lengua extranjera, que dejan el poema en la última página, a la que nunca llegamos por falta de tiempo. Por esta razón, a lo largo de este artículo defenderé trabajar en la explotación de textos poéticos no literatura, sino lengua con literatura, y servirnos de ella no solamente como pretexto cultural o estético.

\section{LA POESÍA EN EL AULA DE L.E.}

La pregunta que se nos impone es la siguiente: ¿por qué el hecho de ver y dedicar tiempo a un poema en una clase de lengua puede generar, en principio, tanto recelo? Las causas de este rechazo, muchas veces inconsciente, pueden explicarse considerando las reacciones de alumnos y profesores. Estos últimos, en un porcentaje elevado, suelen considerar la literatura como un producto complejo de escasa rentabilidad pedagógica. Para ellos esta complejidad entorpece la didáctica, ya que rompe el proceso adquisitivo gradual y relacional que supone el aprendizaje, y con ello favorece la desmotivación en el estudiante. A su vez para el alumno, que también lo rechaza en no pocas ocasiones, el texto puede ser visto como un producto lejano. El estudiante considera este tipo de texto como un 
modelo imposible de (re)producir, pues la diferencia entre sus limitaciones y la perfección del modelo se hacen insalvables y se aleja de sus necesidades de expresión reales (Widdowson, 1985). En otras palabras, para los ojos del estudiante el texto literario supone un impedimento para el aprendizaje rápido y sobre todo rentable que le permita desenvolverse con los nativos en situaciones habituales (Montesa y Garrido, 1994).

Consideradas las reacciones, tendríamos que asumir el hecho irrefutable de que si profesores y alumnos coincidieran en este rechazo, desde luego no habría nada, como señala Widdowson, que pudiera justificar la presencia de la literatura en el aula de lenguas extranjeras, aparte de la intención de enseñar una particular muestra de lengua o de provocar ocasionalmente un deleite, aspecto que, dado su alto valor subjetivo o la distancia sociocultural y lingüística, tampoco garantiza que sea compartido de la misma forma por nuestros estudiantes: "With regard to language teaching, then, neither the purpose nor the process of learning would seem, on the face of it, to provide much justification for the inclusion of literature". (Widdowson, 1985: 181).

Sin embargo, la realidad en el aula nos demuestra que también en ocasiones la literatura, y en nuestro caso la poesía, despierta el interés de los estudiantes, produce satisfacción y estimula la motivación por sí sola. Son muchos los profesores que se han sorprendido por la buena acogida de un poema, o por la petición de los alumnos que desean conocer más sobre el poeta o sobre otros poemas, y que incluso al final de curso piden al profesor un corpus de los textos vistos en clase o le solicitan referencias. El problema por lo tanto no está en los textos, sino en la selección que se haga, los objetivos que se marquen y, como se viene insistiendo, la metodología que se aplique. Todo ello considerando el nivel y las características de un tipo particular de estudiante que tiene el español como lengua extranjera.

En los últimos años el valor de la literatura ha sido subrayado a partir de nuevas perspectivas que defienden su integración en la lengua en todos los niveles de enseñanza. Teorías de la lingüística cognitiva, de la sociolingüística, pragmática o literarias como la semiótica textual o la teoría de la recepción dan un nuevo aire a metodologías basadas en enfoques lingüísticos y críticas literarias de mediados del siglo pasado. La literatura se empieza a concebir como producto cultural y de valor comunicativo, y se pasa del texto absoluto al lector, con el fin de estudiar la relación que establece con ese texto, la recreación del mismo, la multiplicidad de lecturas, las estrategias que elabora o las habilidades que desarrolla.

Desde mediados de los años 80 estas teorías han sido recogidas por numerosos autores, y se han expuesto cada vez con más énfasis en artículos y congresos en pos 
de una defensa de la enseñanza de la literatura en el aula ${ }^{1}$. A su vez las editoriales se hicieron eco de esta tendencia, fruto de la cual fue la aparición de las primeras lecturas graduadas y la inclusión casi sistemática, aunque no siempre, y con tratamientos diferentes, de la literatura en los manuales de ELE. Con ello la poesía volvía a ser reconsiderada como material muy válido para la enseñanza y el aprendizaje de idiomas, y se reelaboraron poco a poco las razones que lo justificaban atendiendo a sus propias características internas. A partir de aquello se argumentaron las siguientes premisas:

1_ Se reconoce el hecho innegable de que la poesía se caracteriza por ser una forma especial de expresión - nadie habla en verso- lo que determina que lleve consigo ciertas licencias para producir efectos, propios del género. Sin embargo, y frente a la crítica que encasillaba al texto poético como algo complejo, se defiende que no toda la poesía es necesariamente difícil. Podemos encontrar magníficos ejemplos de calidad poética con una sencillez en el campo léxico, morfosintáctico y simbólico-referencial que los hace idóneos para ser trabajados en una clase de LE. Si en ocasiones los textos no funcionan es porque a veces son inadecuados para nuestro tipo de estudiantes, lo que hace imprescindible una selección pertinente (y unos criterios $a d$ hoc) que no siempre se hacen.

2 La poesía genera una alternativa al contacto que habitualmente tiene el estudiante con la lengua. La propia constitución del texto literario produce en sí mismo una ventaja y no una rémora que entorpezca la adquisición de un idioma. Como sabemos el poema ofrece un mensaje fuertemente subjetivado, donde prima la interiorización. El estímulo que se produce parte de uno mismo y no del exterior, lo que lleva a personalizar el mensaje. Esto se debe a que en la poesía no hay intercambio con el interlocutor a través de una comunicación, sino una reconstrucción personal del mensaje a través de la expresión. Es lo que Montesa y Garrido llaman "función de comunicación" y "función de expresión del lenguaje", de la cual se haría cargo la literatura (1994: 450). Si en un principio el profesor y el estudiante están preocupados principalmente por la primera con el fin de satisfacer sus necesidades de comunicación más inmediatas, pronto se revela que el ser humano tiene también la necesidad de expresarse a sí mismo y de identificar su pensamiento y sus emociones. Insertar la literatura en el aula no es dar solamente variedad al aprendizaje, sino ofrecer una respuesta a realidades menos visibles que inconscientemente $-\mathrm{O}$ a veces conscientemente- demandamos todos.

3_ La poesía tiene casi siempre una extensión corta y está contextualizada en sí misma, lo que nos permite abarcarla en su totalidad en clase. Proporciona además un contacto con los recursos expresivos del idioma en sus dimensiones connotativa

${ }^{1}$ Véanse los estudios de Maley, Duff, Brumfit, Collie, Slater, Moulding, Hill, Lazar o Widdowson en el círculo anglosajón, o de Mendoza Fillola, Montesa, Garrido, Acquaroni, Cassany, López Valero, Sanz Pastor, Naranjo o Quintana en España, entre otros. 
y denotativa que el estudiante descubre, reelabora y comparte gracias a la ambigüedad del mensaje poético. Esta ambigüedad favorece la variedad de interpretaciones y con ello el intercambio de puntos de vista y de lecturas sobre un mismo texto. Al recrear y construir el mensaje en función de las experiencias vitales de cada uno y del conocimiento personal del mundo, ninguna interpretación individual del estudiante puede ser completamente desestimada ni considerarse como la opción inequívocamente correcta. De este modo, la validez "a priori" de lecturas genera una motivación en el alumno para lanzarse a negociar o defender su punto de vista.

4_ El poema es siempre un producto social y humanístico que implica al estudiante (en su inteligencia y afectividad $^{2}$ ) y activa sus conocimientos y procedimientos internos (culturales, lingüísticos, cognitivos y estratégicos) en busca de la aprehensión literal y literaria del poema. Esta reacción en el lector se convierte en nuestra aliada, ya que aumenta su interés por la cultura en la que se inserta el texto (convertido en escaparate y ventana de su mundo), y facilita a su vez el contacto y la adquisición inconsciente de vocabulario, así como de referencias o estructuras lingüísticas que surjan en y desde el texto.

5_ Finalmente, y no menos importante, la lectura de un poema puede ser responsable de un placer estético y lleva incluso a una reflexión o pensamiento crítico, nacido de una idea compartida, del matiz o del rechazo.

\subsection{Hacia la praxis}

Consideradas sus cualidades y ventajas, la implantación de los textos poéticos en los manuales de E/LE y su aplicación actual en el aula en los últimos años se ha hecho, como se ha apuntado, de forma tímida, aunque siempre progresiva. Hoy en día una buena parte de los manuales que se editan en España recogen alguna muestra literaria, fundamentalmente cuentos y poemas, ofreciendo un tratamiento y un grado de integración en el contenido de la unidad que aumenta progresivamente conforme la publicación es más reciente (Acquaroni, 2007: 52). Sin embargo, considerando los textos poéticos, lo primero que sigue llamando la atención en los manuales es la posición y la explotación desigual con que se desarrollan. En muchos de ellos los textos ocupan una posición testimonial, dispuestos en ocasiones al final de la unidad como actividad cultural excelsa, casi a modo de reclamo, sin sacar muchas veces relación con el contenido de esa unidad, y sin ofrecer apenas propuestas didácticas. Aspectos que, no es casualidad, revelan todavía, como sostenía Acquaroni, "las dificultades que dicho material plantea al profesor para incorporarlo realmente al desarrollo de la clase" (1997: 17).

${ }^{2}$ Es lo que se ha llamado por algunos autores:«la apropiación efectiva y afectiva del texto» (Acquaroni, 2000: 61-63), o «proceso intelectivo y afectivo» del lector, (Montesa y Garrido, 1994: 455-56) 
Esta realidad muestra que las nuevas reflexiones conllevan necesariamente una respuesta metodológica que no siempre se ha sabido adoptar en el aula. Ante la falta de una metodología clara, en numerosas ocasiones el tratamiento de la literatura en las clases de E/LE se ha importado del que se viene haciendo en contextos de lengua materna, elaborando de este modo preguntas muy poco adecuadas al tipo de estudiantes al que va dirigido el poema. Tradicionalmente este tipo de preguntas suelen orientarse de dos formas: bien hacia contenidos lingüísticos o literarios de tipo filológico irrelevantes o desconocidos para un estudiante no especializado necesariamente en ese campo; o bien hacia planteamientos con presupuestos de conocimiento compartido que no son reconocibles ni tan evidentes por un extranjero, máxime cuando las circunstancias de la vida $u$ obra del autor pueden estar muchas veces condicionadas por aspectos culturales de la comunidad histórica a la que pertenece.

Generalmente la explotación de textos poéticos en E/LE atiende más a la forma (aspectos gramaticales, léxicos) o al contenido (pretextos comunicativos) dependiendo de las corrientes metodológicas en las que se inserta. Estos procedimientos de actuación revelan en última instancia la finalidad que se le da al poema, y por extensión el uso que se pretende hacer de la literatura (lingüístico, cultural o puramente artístico / literario), con predominancia o no de unos sobre otros $^{3}$. En cualquier caso, llama la atención cómo uno de los aspectos más recurridos en la explotación de este tipo de textos en el aula de E/LE sea proceder con una batería de preguntas para evaluar la comprensión lectora. Con ello se quiere saber si el estudiante ha entendido la literalidad, estableciendo criterios de comprensión como si fuera necesario hacer un trasvase de datos y contenido sin ningún criterio didáctico. Son frecuentes de este modo las preguntas configuradas de forma cerrada para admitir una única respuesta que obliga a reproducir -a veces literalmente- un verso o frase del texto, aunque a veces ni siquiera se entienda.

Llegados a este punto, yo defiendo que más que pedir, es mejor contribuir a la comprensión del texto. Utilizar preguntas más abiertas que permitan la reconstrucción del poema, y apropiarse a continuación de técnicas que nos lleven a la expresión y creatividad desde el texto, favoreciéndose de los procesos creativos e interpretativos que ofrece la literatura. No se trata, en definitiva, de dirigir el poema hacia la comprensión como único objetivo, sino servirnos también de ella como mediador hacia la práctica más amplia de otro tipo de posibilidades y destrezas, contribuyendo al enriquecimiento del conocimiento cultural y literario del alumno.

Para ello es indispensable respetar el texto como lo que es: un producto literario. La diferencia de esta técnica respecto al tratamiento al uso de la mayor parte de los ${ }^{3}$ Véase en este sentido la tipología de finalidades que establece Juárez Morena (1998: 277-
278). 
manuales estriba en que trabajamos contenidos culturales, políticos, sociales y lingüísticos sin tocar el poema, y no viceversa, lo que nos permite preservarlo para el fin último del placer estético y la degustación de su valor literario, sin convertirlo en un mero pretexto. Precisamente, uno de los grandes problemas en la explotación de textos literarios en el aula de E/LE ha sido la ausencia de una explotación específica atendiendo a su particular naturaleza (Garrido y Montesa, 1991: 76). Y es que tradicionalmente los textos poéticos en particular, y literarios en general, han sido explotados en base a los mismos criterios que se han venido aplicando para la explotación de otro tipo de textos.

No hay que olvidar que los textos no literarios utilizados normalmente en el aula, ya sean fabricados expresamente o recogidos de muestras auténticas de lengua, proveen de una fuente de información lingüística y sociocultural elegida para ser explotada con fines didácticos. Este tipo de textos aparece de este modo para presentar o ejemplificar determinados elementos de una forma observable, a través de un input escrito. Sin embargo los textos literarios no pueden abordarse del mismo modo que los textos convencionales. Su objetivo no es presentar vocabulario, ni estructuras gramaticales, ni usos de la lengua, ni contenidos específicamente culturales o pragmáticos. Ésta fue precisamente la consideración que hizo la metodología tradicional sobre la literatura, tomada como medio privilegiado para llegar a la lengua. Aspecto que, no es casualidad, fuera motivo para provocar una reacción pendular en la historia de la enseñanza de lenguas, que la hizo desaparecer, como vimos, durante un tiempo del aula.

La literatura juega con todos los recursos para producir un efecto, comunicar y transmitir un sentido que van mucho más allá del valor expositivo y didáctico, ya que no está concebida para eso. Como sostienen Jurado Morales y Zayas Martínez (2002: 24), "los textos literarios no se dirigen al alumno como alumno de la lengua, sino como lector". De ahí que los textos literarios deben ser respetados y abordados como son: literatura, estableciendo una metodología diferente al respecto que no parta de ellos para explicar o aprender la lengua, sino que se sirva de la lengua para llegar a ellos. Perderíamos su valor si los utilizáramos únicamente para explicar una estructura sintáctica o aprender un adjetivo. Al margen de determinadas actividades que parten desde el texto (actividades durante la lectura, que también veremos), y que en ocasiones pueden ser muy válidas, la explotación de textos literarios debería centrarse especialmente en actividades previas y posteriores a la lectura, sin excederse en cualquier caso de las manipulaciones o usos parciales que a veces se hacen sobre ellos.

Mi propuesta es que el uso y aprendizaje de una lengua -sirviéndonos en este caso de un texto literario- puede hacerse de un modo que respete lo máximo posible la integridad y propiedad del texto y a su vez "se sirva de él" para ese aprendizaje. Propongo de este modo que la lengua no se aprenda con el texto, sino preferiblemente en el proceso que va hacia el texto y desde el texto, a través sobre todo de actividades previas y posteriores al mismo. Es decir, utilizar un texto -en 
este caso un poema- como reclamo para hacer actividades preparatorias que faciliten su recepción y permitan la práctica y el aprendizaje, y que a su vez sirva como estímulo para hacer actividades provocadas tras su lectura, desde la creatividad y la interpretación, atendiendo a los mismos objetivos.

Con la intención de establecer una metodología para la explotación de textos poéticos, se elabora a continuación una lista de criterios de selección, acompañada de un corpus con propuestas de actividades previas a la lectura, durante la lectura y posteriores a la lectura, que el profesor podrá elegir conjugando siempre las características del poema elegido con el nivel lingüístico, las necesidades, la experiencia lectora y las motivaciones del grupo. En este sentido existen en el mercado editorial tres libros con un corpus de técnicas y actividades de explotación que resultan referenciales en este apartado, y que aquí considero en parte: The inward Ear. Poetry in the language classroom, de Alan Maley y Alan Duff (1989); Literature (1990: 157-165) escrito por los mismos autores; y La poesía como instrumento didáctico en la clase de E/LE, de María Naranjo (1999), libro basado en los anteriores con vistas a realizar una aplicación en la poesía en lengua española, ofreciendo un excelente corpus de actividades ejemplificadas a través de numerosos poemas.

Considerándolo todo, se ha de recalcar que mi propósito está lejos de defender la necesidad de trabajar de forma sistemática con un poema en el aula, ni de privilegiarlo sobre otro tipo de textos, también importantes. La única intención que me mueve es dar variedad al aprendizaje y resolver, como vimos, otras necesidades que puede tener el alumno sobre las posibilidades expresivas de la lengua que aprende. En definitiva, subrayar su importancia y, junto a ello, dotarlo de medios para una aplicación pertinente dentro del nuevo contexto en el que la literatura se mueve.

\section{PROPUESTAS METODOLÓGICAS}

\subsection{Selección}

Tal y como apuntamos en el punto 1 del artículo, una de las claves para el éxito en la recepción de un poema por nuestros estudiantes es la selección que se haga de los textos. Como señalan Maley y Duff (1989: 5), en este punto el profesor debe considerar siempre que el material seleccionado debe estar orientado a una clase de lengua, y no a un curso de apreciación literaria, recordando que: "a poem does not always have to be "good" (whatever that may mean!) in order to be useful. Nor does the teacher need to be a poet in order to use poetry".

En esta línea, uno de los aspectos fundamentales en la selección de material poético, como señala Acquaroni, "es que los textos que seleccionemos tengan algo que transmitir a nuestros estudiantes y que puedan promover su participación activa en las actividades que se propongan sobre ellos" (2007: 80). Junto a éstos, deberían superponerse otros criterios como la capacidad de promover el interés de los alumnos, la claridad del texto, sus características internas -lingüísticas y 
temáticas-, o la potencialidad didáctica que puede desprenderse de todos ellos, como a continuación veremos. Por esta razón, lejos de establecer férreos criterios dogmáticos o de guiar al profesor por la senda de determinados poemas, épocas o autores, deberá entenderse que la selección de textos no atiende necesariamente a un único aspecto, sino que con frecuencia es una acumulación de varios o de todos ellos. A continuación se proponen en este apartado tres grandes criterios que pueden y deben tenerse en cuenta a la hora de elegir un texto poético para la clase de E/LE:

\section{Criterios lingüísticos y literarios}

a) Es conveniente que los poemas no presenten un desequilibrio entre su composición interna y el nivel del estudiante al que van dirigidos. Quiere decir que los planos morfo-sintácticos, léxico-semánticos y referenciales que integran el poema deben ser suficientemente accesibles al estudiante tanto en su estadio de literalidad textual, como $-\mathrm{y}$ esto es lo más importante- en el posterior plano literario de la interpretación y degustación del mensaje poético. Los estudiantes deben poder disfrutar de la literatura, y eso solo es posible si en la lectura entienden y recrean el texto.

En este sentido es preciso indicar que así como la recepción del plano lingüístico puede ser más o menos común a todos los estudiantes -en un grupo ideal de nivel homogéneo- y depende del grado de dominio de la lengua extranjera que se estudia, el plano referencial está relacionado con la experiencia y madurez lectora del estudiante en su L1. El profesor debe tener en cuenta que los textos elegidos deben ser por lo tanto adecuados al nivel del estudiante en el contenido lingüístico (literalidad) y no demasiado obscuros en cuanto al significado expresivo (literariedad), para que puedan ser accesibles a todos ellos.

Respecto al contenido lingüístico, es importante señalar la necesidad de no caer en análisis exhaustivos destinados a explicar y comprender cada uno de los elementos del vocabulario o de las estructuras gramaticales. Estas prácticas, habituales en el aula, suponen una visión reduccionista que elimina la flexibilidad, dinámica y rentabilidad de otras actividades diseñadas para acercarse gradualmente a la comprensión e interpretación del texto, a través del uso de otras técnicas más variadas y motivadoras. En esta línea, tal como señala Mendoza Fillola (1998: 14),"leer es bastante más que saber reconocer cada una de las palabras que componen el texto: leer es, básicamente, saber comprender, y, sobre todo, saber interpretar, o sea, saber llegar a establecer nuestras propias opiniones, formuladas como valoraciones y juicios". Por esta razón nuestra labor como docentes no debe dirigirse a desentrañar el texto, sino a facilitar su recepción, garantizar su posible degustación respetando el texto, y servirnos de sus cualidades para trabajar a partir del mismo y de las interpretaciones que ha ido sugiriendo.

b) Relacionado con el vocabulario, se recomienda abordarlo considerando siempre dos criterios: el de frecuencia (comenzar por el vocabulario más frecuente 
que pueda ser utilizado en un futuro), y el de utilidad (comenzar por el vocabulario más útil), anteponiendo siempre el estudio de las palabras que consideramos clave para la comprensión del texto. El estudio de palabras que no puedan ser rentabilizadas por el estudiante y que tampoco son indispensables para la comprensión del texto pueden ser omitidas por el profesor siempre que los estudiantes lo permitan. Por otra parte es preferible que en la selección de textos se valore que el vocabulario no sea arcaico ni demasiado especializado. En caso contrario es muy importante que el profesor señale las palabras que están fuera del uso actual y habitual por parte del hablante nativo.

c) Es recomendable que los poemas tengan una estructura sintáctica sencilla, próxima al lenguaje coloquial. Este punto es de vital importancia puesto que el género lírico, en busca del efecto rítmico, concede por antonomasia numerosas licencias en el plano morfosintáctico.

d) Los criterios de selección lingüísticos (búsqueda de una determinada estructura sintáctica, de un vocabulario concreto, de una determinada rima o efecto fonético), tan frecuentes en la selección de textos literarios, y concretamente poéticos, no pueden ni deben ser los únicos para elegir estos textos.

\section{Criterios didácticos}

a) La elección de un texto debe hacerse considerando siempre el interés que puede suscitar en los alumnos, en función de sus motivaciones, sus necesidades y sus preferencias. Por la misma razón, es también muy importante que el diseño de explotación didáctica sea flexible y abierto, con el fin de que el profesor tenga margen para reorientar, suprimir o introducir sobre la marcha actividades a partir de la reacción que el texto y la dinámica marcada vaya produciendo en los estudiantes.

b) Es preciso destacar cómo en numerosas ocasiones los profesores eligen textos literarios atendiendo a criterios que pueden producir por sí mismos desmotivación en el alumno, lo que debe llevar a un necesario replanteamiento que puede hacerse del modo siguiente:

1. El profesor elige el texto en función de sus preferencias y sus gustos, sin valorar realmente cuáles son los del alumno. Se hace necesario por tanto que el profesor conozca los hábitos de lectura de sus estudiantes, además de sus preferencias temáticas acordes a su edad, experiencias vitales o intereses personales.

2. La elección del texto por parte del profesor se hace en función de una finalidad que atiende a aspectos específicos, dirigidos y didactizados por el profesor en función de las cualidades que encuentra en ese texto. Estos aspectos hacen referencia al contenido, estilo, adecuación temática o recursos lingüísticos. Sin embargo, el problema surge cuando el profesor intenta controlar toda la dinamización, y da poca libertad al estudiante por el empleo de explotaciones muy dirigidas y 
predeterminadas que intentan no desviarse de la lista de elementos que deben ser analizados. En la explotación de textos literarios, y poéticos en particular, la multiplicidad de lecturas que surgen del texto y la posibilidad de que el estudiante pueda aportar su interpretación son ya en sí mismos factores extremadamente motivadores que el profesor debe enfatizar, subrayando el protagonismo de sus estudiantes.

3. La explotación de textos en el aula de LE sigue utilizando pautas de análisis académico heredadas de la $\mathrm{L} 1$, dispuestos en forma de comentarios al uso, preguntas de comprensión o estudios metalingüísticos o metaliterarios que condicionan desde su inicio la recepción del texto. Aspecto que, tanto en L1 como en LE, presenta serias repercusiones en la motivación del alumno. Como señala Mendoza Fillola, este tipo de explotaciones limita además las funciones de la lectura, puesto "que el lector solamente actúa para poder dar cuenta de que efectivamente se ha leido, analizado y entendido el texto, ya que pocas veces se atiende a preguntar sobre si se ha disfrutado o no con la lectura, y son limitadas las ocasiones en que se invita al alumno a explicar sus razones sobre este último punto" (1998: 42-43). Con ello, el pretendido goce anunciado, la recepción estética o los comentarios o actividades iniciales para captar el interés o la atención lectora, quedan desdibujados por el uso reducido que se hace del texto y por la falta de aplicación de actividades centradas en el alumno, verdaderamente comunicativas, que estimulen de forma efectiva la recepción y el interés por el texto, que faciliten el placer estético que quizás se encuentre en su lectura, que respeten la integridad del texto, y que lo utilicen también como pretexto, considerando sus posibilidades interpretativas. Y es que, como señala más adelante Mendoza Fillola (1998: 44):

Se deja de lado la espontaneidad de la expresión de opiniones personales y de los comentarios informales (...). Como efecto, puede suceder que el alumno encuentre a faltar el componente lúdico añadido que surgía de la puesta en común de valoraciones, interpretaciones, de comentarios verbales en grupo, de juegos correlacionados con la lectura. Según estos supuestos, hay que advertir, críticamente, que se habrian creado unas inadecuadas expectativas sobre el potencial aporte de la literatura.

c) Es muy recomendable que los textos poéticos sean auténticos y no adaptados por el profesor con la intención de favorecer la comprensión de los mismos. Las propias características del poema hacen que la elección y colocación 
de las palabras, o la manipulación tanto de la estructura sintáctica como de las correlaciones semánticas se hayan hecho de esa manera y no de otra para producir un efecto, creando un código propio lleno de flexibilidad y de tolerancia a la irregularidad normativa que el profesor debe respetar para no romperlo. Con ello se propone al estudiante una nueva forma de ver y de sentir la lengua a través de un producto original, tal y como fue creado.

d) La elección de textos poéticos, realizada por el profesor en función de sus cualidades temáticas, lingüísticas, emocional-afectivas, de acción, de contenido, o estilísticas, debe saber aprovechar la potencialidad didáctica que llevan dentro. Para ello es necesario que el profesor conozca y aplique las actividades y técnicas que permitan explotar de forma pertinente las posibilidades que ofrece el texto. Como señalan Duff y Maley (1990:157), en muchas ocasiones los profesores no suelen tomarse el tiempo de ver más allá del ejemplo de explotación específico y la aplicación directa en un aquí y ahora del texto que se lleva a clase. La clave por tanto no está en tratar esos textos y sus actividades como casos aislados, sino en desarrollar técnicas y generar recursos generalizables en cualquier texto. Con esa intención se propone en las siguientes páginas un inventario de procedimientos de explotación poética para la clase de LE.

\section{Criterios temáticos}

a) Es preferible que los poemas tengan referentes actuales, interculturales o universales reconocibles por los estudiantes. Como señalan Maley y Duff, los referentes universales permiten partir de una experiencia y conocimiento vital comunes a todas las culturas, aunque pueden diferir en el modo de ser tratados (1989: 8). Esto permite desarrollar la curiosidad, la empatía y el análisis intercultural, a la vez que se fomenta la recreación y la reflexión sobre la pluralidad de vivencias y de puntos de vista entre diferentes individuos, sociedades y culturas. Algunos de estos referentes universales que son a la vez tan personales y culturalmente quizás tan distintos pueden ser: amor, vida, muerte, relaciones personales, relaciones con el entorno, aspectos cotidianos, amistad, vejez, memoria, (des)esperanza, etc.

b) Es preciso tener en cuenta que los referentes actuales por su parte (acontecimientos históricos, políticos o socioculturales entendidos en forma de normas, valores, costumbres, modos de vida o convenciones sociales) facilitan el acercamiento al texto en mayor grado que las referencias históricas o excesivamente particulares de la cultura en la que el poema se mueve, salvo que por sus características las referencias reflejen determinados hechos históricos o aspectos socioculturales específicos que resulten de interés para los estudiantes. En esta línea, los alumnos suelen estar más identificados con los autores y textos 
contemporáneos (es decir, publicados a partir del XX), ya que los sienten más cercanos, aunque esto no elimina en absoluto la posibilidad de trabajar con autores y textos clásicos, siempre y cuando se cumplan los criterios que se han establecido en este capítulo.

\subsection{Explotación}

\section{Actividades de Prelectura}

Las actividades de prelectura han sido tradicionalmente las más olvidadas en la explotación de textos poéticos, a pesar de que son las más importantes, especialmente si nos remitimos al campo de lenguas extranjeras. Sin estas actividades, el poema, por muy apropiados que sean los criterios de selección, corre riesgo de fallar en su recepción, con lo que la explotación posterior resulta más difícil. La razón es que los estudiantes no han sido convenientemente estimulados y pueden bloquearse al procesar de golpe una información para la que no estaban preparados. En otras palabras, sin unas actividades de preparación adecuadas podemos estropear todo el proceso de recepción y posterior explotación didáctica. Dedicar un poco de tiempo, aunque sean 5 minutos, es aumentar enormemente el éxito, la degustación y la utilidad del poema.

El propósito de las actividades de prelectura es favorecer el acceso al texto y dar un sentido a la lectura, creando a su vez un clima de relajación y confianza para trabajar el poema en clase. Por regla general, unas buenas actividades de prelectura deberán considerar siempre tres aspectos: 1) La activación del conocimiento previo del estudiante, de manera que los estudiantes sean conscientes de lo que saben y el profesor sepa lo que éstos necesitan; 2) La motivación mediante la creación de expectativas; y 3) La contextualización, proveyendo de un determinado adelanto de la información implícita o explícita del texto, y con ello revisando, actualizando o corrigiendo llegado el caso, las posiciones y percepciones sobre los elementos presentes o sugeridos en el texto y la cultura meta.

Las actividades de prelectura ayudan a su vez a hacer más rápido el proceso de descodificación que los estudiantes de L2 realizan sobre el texto, ya que siempre resulta más lento y difícil que el de un lector diestro y nativo (Ballester Bielsa, 2000:66). Para ello se estimula su conocimiento lingüístico y del mundo, se ayuda a desarrollar sus estrategias de lectura y se apoya en su procesamiento cognitivo. El objetivo en definitiva es ayudar al estudiante a extraer no sólo un significado, sino a favorecer la búsqueda de sentido en la interpretación e interacción que haga con el texto en su proceso recreativo. Todo, como se ha dicho, a partir de su conocimiento, de sus habilidades y de sus experiencias previamente estimuladas con las actividades que aquí planteamos. Con este propósito, divido las actividades en dos grupos: 
a) Las que se sirven del texto para promover la hipótesis y la predicción de los estudiantes a partir de elementos explícitos del texto (título, versos, vocabulario, etc.). Son las que llamo: Actividades de predicción.

b) Las que sirven para contextualizar el texto a partir de su temática y sus elementos implícitos (contenido), que aquí llamaré: Actividades de contextualización.

En cualquiera de los dos tipos de actividades, hay que tener en cuenta que el profesor debe dirigir a sus alumnos hacia la temática y contenido del poema, de manera que se creen expectativas y puedan adelantarse contenidos que facilite el posterior acceso de los estudiantes al texto (vocabulario, gramática, estilo, historia, cultura, etc.).

\section{- II. Actividades de Predicción}

1. Se da a los estudiantes el título del poema, y éstos tienen que hacer hipótesis sobre el tema y el contenido. La actividad se realiza en grupos o de forma plenaria, primero escrita y luego -o solo- de forma oral, dependiendo del tiempo disponible. Asimismo, junto con el título, el profesor puede proporcionar también posteriormente el primer verso del poema.

2. El profesor da el nombre o las características (sexo, edad, profesión) de los personajes que puedan aparecer en la historia, así como el lugar de acción donde se desarrolla la misma. Los alumnos, de forma similar al punto anterior, intentan reconstruir la historia y adivinar el tema.

3. El profesor escribe dos frases contrapuestas de manera que sólo una está presente en el poema. Los alumnos tienen que decidir cuál es la frase o verso que aparece y en función de la misma recrear una historia, introduciendo acción y personajes.

4. Los alumnos escriben una pregunta al protagonista o autor del poema haciendo referencia al posible contenido. Tras la lectura deberán comprobar si el poema les da la respuesta.

5. El profesor escribe una cita o refrán célebre incompleto, cuya reconstrucción resume de forma cierta o antitética una parte o la totalidad del contenido del poema. A partir de aquí, los alumnos deben adivinar el final del refrán o de la frase, decidir si se aplica o no al poema, y hacer hipótesis sobre el dónde, cuándo, quién, cómo y por qué del contenido del texto.

6. El profesor proporciona vocabulario y estructuras gramaticales claves del texto con el fin de que los estudiantes predigan la temática y el posible contenido. 


\section{III: Actividades de Contextualización}

1. El profesor presenta a los estudiantes artículos, relatos cortos, titulares de noticias, anécdotas o experiencias relacionadas con el contenido del poema. El objetivo es discutir sobre ellas extrayendo opinión, vocabulario, estructuras gramaticales e información, como medio para compartir el conocimiento sobre el tema y relacionarlo posteriormente con el poema.

2. El profesor presenta elementos históricos, sociales, políticos o personales que aparezcan en el poema. Posteriormente se intenta relacionarlos con la experiencia de los estudiantes con el fin de crear un debate cuyo contenido se acerque a algunos de los aspectos tratados por el poema. Durante la práctica el profesor provee de vocabulario que aparece en el texto.

3. El profesor presenta una pequeña biografía del poeta y lleva a los estudiantes ante posibles aspectos que motivaron, si es el caso, la composición del poema que se va a tratar en clase. Los estudiantes infieren, a partir de la vida o experiencias del poeta, posibles temáticas, tratamientos o contenidos del poema.

4. El profesor provee a los estudiantes de fotos, dibujos o cuadros relacionados con el tema del poema. También puede hacer referencias a películas o libros que recojan una historia similar planteada en el mismo. El objetivo es llegar al poema mediante la comparación y la reconstrucción.

5. Como actividad más directa, se introduce el poema situando a los estudiantes directamente en las referencias en las que se mueve su contenido. A partir de ahí se abren campos temáticos y semánticos, tormentas de ideas, diagramas, mapas conceptuales, en las que surja vocabulario que puede aparecer en el texto o que adelante el profesor. Posteriormente se hace un debate a partir de las experiencias de los estudiantes, primero dispuestos en parejas o ya directamente de forma plenaria.

\subsection{Actividades durante la lectura}

Las actividades confeccionadas para su aplicación durante la lectura del texto son las denominadas actividades de reconstrucción. Por sus características, estas actividades actúan directamente sobre el texto en su proceso de recepción, ya sea modificándolo, adelantando alguna de sus partes, eliminando elementos, etc. Resulta indudable por tanto que estas actividades no posibilitan una recepción íntegra del texto, tal como fue concebido y aquí se ha defendido, por lo que el profesor deberá tener especial cuidado con caer en explotaciones excesivas y reduccionistas de este tipo. No obstante, estas actividades, que se sirven muy especialmente de las características del poema, pueden utilizarse en ocasiones de forma muy efectiva como recurso lúdico y pedagógico. Algunas de estas actividades son: 
1. Convertir una parte del poema en prosa sin signos de puntuación, de manera que los alumnos lo versifiquen marcando las comas, los grupos fónicos (si trabajas la pronunciación), etc. y lo comparen con el original.

2. Proporcionar una parte del poema, de manera que los alumnos hagan predicciones sobre su posible continuación. La parte proporcionada puede ser el comienzo, un fragmento intermedio o incluso el final.

3. Reconstruir el poema verso a verso. Para ello el profesor proporciona el primer verso del poema de modo que los estudiantes imaginen cómo continúa en el segundo. El profesor compara su respuesta con el original y así sucesivamente.

Como vemos, no se incluyen aquí de forma deliberada algunas de las prácticas más habituales y tradicionales, pues, salvo excepciones, no las considero por lo general apropiadas para este tipo de textos. Normalmente la práctica más extendida a la que se hace referencia es eliminar palabras del poema (léxico, categorías gramaticales -adjetivos, nombres, verbos, preposiciones, adverbios, etc.) con el fin de trabajar alguna de estas opciones: a) que los alumnos elaboren hipótesis completando los huecos); b) que las palabras eliminadas sean sustituidas por dibujos o fotografias que las representen, de modo que los alumnos las identifiquen a partir de estas pistas.

\subsection{Actividades posteriores a la lectura}

Las actividades posteriores a la lectura se han limitado tradicionalmente a evaluar la comprensión del texto, considerando al estudiante un receptor pasivo que debía interpretar correctamente, sin preocuparse demasiado por lo que los estudiantes pudieran decir sobre los textos. Dicho de otro modo, no se valoraba la participación del estudiante, ni su intervención, ni sus aportaciones, sino la interpretación dogmática del texto. Aunque no se niega la en ocasiones necesaria dirección crítica del profesor en los momentos de relajación y banalización en la lectura del mensaje poético, el texto no puede concebirse como un producto de evaluación unívoca de datos, aspecto que, como vimos, va en contra de su propia capacidad e idiosincrasia (Eco, 1992).

Las actividades posteriores a la lectura deben servirse de la potencialidad del poema para favorecer la creatividad, el intercambio de lecturas, la negociación de significado, la expresión del sentimiento, la descripción del placer estético, el aprendizaje lingüístico (sin ser pues el único objetivo), la comparación sociocultural, o la percepción del ritmo y la musicalidad. Son tantas las posibilidades que otorga el texto poético que centrarnos en la validación del significado o en la adquisición de vocabulario -sin negar su importancia- es despreciar su riqueza. Por eso las actividades posteriores a la lectura resultan un maravilloso pretexto para servirnos del texto. Para llegar de él a la lengua en un ámbito diferente de interiorización y expresividad que ningún otro tipo de texto 
puede promover en la conciencia del estudiante. Para facilitar, en definitiva, que los estudiantes tengan un contacto diferente con la lengua.

Sin caer en una lista exhaustiva que está fuera del propósito de este artículo, se señalan algunas de las actividades que me han dado mejor resultado, divididas en cinco apartados: a) actividades de expansión; b).de transformación; c) de relación; d) de sustitución; y e) de debate. Es elección del profesor elegir aquéllas que, según las características y posibilidades del poema, mejor se adapten tanto a los objetivos docentes como al nivel lingüístico y a las necesidades del grupo, dando preferencia a actividades de tipo lingüístico o comunicativo, o simplemente conjugando ambas.

I. Actividades de Expansión (Estimulan la creatividad y favorecen la toma de decisiones del estudiante)

a) Continuar el poema, comparar los resultados, y elegir entre todos la continuación más original o bonita.

b) Representar monólogos (voz en off), diálogos o acciones que aparezcan en el poema asumiendo la personalidad del autor omnisciente, del protagonista o de los protagonistas. Los alumnos pueden añadir elementos a la historia.

c) Adoptar el punto de vista o la conciencia de un personaje de la obra y elaborar un texto paralelo. Ese texto puede estar dirigido a cualquiera de los otros personajes del texto o a uno mismo (la voz de la conciencia en su monólogo interior).

d) Crear o expandir diálogos, situaciones o circunstancias de los personajes que aparecen en el poema. Crear e incluir nuevos personaje y descripciones. Puede hacerse por escrito o representado ante la clase.

e) El profesor pide a los estudiantes que imaginen que, dado el caso, ese poema ha sido dirigido a ellos. A continuación deben escribir una carta de respuesta al poeta como si fuesen ellos los interpelados. Los resultados se intercambian entre los estudiantes.

f) Escribir una carta al protagonista o a cualquiera de los personajes que aparecen en el poema, aconsejándoles, recriminándoles, animándoles, etc.

g) Investigar aspectos sobre la vida, obra o circunstancias históricas, sociales o políticas relacionadas con el autor y su época. En cursos avanzados pueden trabajarse incluso teorías sociales y filosóficas relacionadas con el estado de ánimo del protagonista, las dinámicas socioculturales, la concepción de la vida, o la moral y la ética presentes en el contenido del poema.

h) Escribir una historia desde el punto de vista de un objeto relevante que aparezca en el poema. El estudiante tiene la libertad de 
completar, añadir e inventar cosas, pero obligado a partir de la información dada en el texto.

i) Elaborar un texto utilizando algunas de las palabras presentes del poema. En los casos en los que se permita, manejar algunas de las estructuras gramaticales del poema para crear nuevos versos a partir de esas estructuras.

j) Dar título al poema (si el profesor no lo ha proporcionado) o sugerir otro título en caso de que los estudiantes ya lo sepan.

k) Poner música al poema y/o compararlo con versiones musicales si hubiese disponibles (Paco Ibáñez interpretando poemas de Lorca, Cernuda, etc.); Serrat cantando versos de Miguel Hernández o Antonio Machado; Amancio Prada cantando versos del romancero viejo o de San Juan de la Cruz; Enrique Morente poniendo cante a versos de Lorca, Rafael Alberti, Miguel Hernández, Cernuda, San Juan de la Cruz, etc.

1) Leer el poema en voz alta y valorar lo que los estudiantes han sido capaces de entender y recordar.

m) Aprender algunos versos o estrofas. El profesor puede hacer una cadena sonora, de modo que cada estudiante se aprende primero un determinado número de versos y posteriormente los recita en el momento que le toca, tras su compañero. Éste es un mecanismo muy efectivo para concienciarse del ritmo y musicalidad del poema, y una buena oportunidad para trabajar en grupo la prosodia (ritmo, entonación, tempo, pausas) durante la recitación sin texto.

II. Actividades de Transformación (Proveen al estudiante con la experiencia de la manipulación del idioma en función de la perspectiva comunicativa)

a. poética, establecer los versos.

b. Cambiar el punto de vista (de primera a tercera persona o viceversa).

c. Cambiar el estilo directo por estilo indirecto o viceversa.

d. Cambiar el tono del poema (de optimista a pesimista, de enamorado a desengañado, de tranquilo a agresivo, etc.).

e. Cambiar las características o el sexo de los personajes.

f. Cambiar el final del poema creando otro alternativo. El resultado se compara entre los estudiantes y se elige el mejor.

g. Cambiar algunas de las situaciones que pueda describir el Convertir el texto poético en prosa. En el caso de la prosa poema (cambio de lugar, de tiempo, de acción).

h. Convertir el poema en una noticia de periódico, un diario personal, una historia de horror, un cuento de hadas, etc. 
III. Actividades de Relación (desarrollan la asociación y correspondencia de significados mediante la comparación y el contraste)

a. Relacionar el poema con fotos, cuadros, textos (novelas, cuentos, otros poemas), refranes, canciones o materiales audiovisuales (películas, series, etc.) tanto del mundo hispanohablante como otros que el estudiante conozca. Mostrarlo, compararlo, justificarlo y describir las sensaciones que provoca.

b. Asociar palabras del poema por significado o tema y elaborar campos temáticos.

c. Establecer un corpus de sensaciones asociadas al poema. Describir esas sensaciones.

$I V$. Actividades de Reducción (desarrollan la capacidad de síntesis, la selección y la reelaboración de ideas)

a. Condensar el contenido del poema en un titular de periódico o en un eslogan publicitario.

b. Reelaborar una versión reducida del poema utilizando las palabras clave presentes en el poema $y / u$ otras que sinteticen su contenido.

c. Elaborar un haiku sintetizando el contenido del poema. Comparar los resultados entre los estudiantes de la clase.

$V$. Actividades de Sustitución (Promueven la reflexión de los estudiantes sobre el valor de las palabras y la repercusión -y responsabilidad- de su elección para la formación de significado)

a. Sustituir algunas de las palabras del poema por otras, utilizando sinónimos o antónimos. El profesor puede aportar una lista de sinónimos o antónimos ya establecida.

b. Sustituir algunas de las estructuras gramaticales, conectores de discurso, etc., por otras semejantes o totalmente diferentes.

VI. Actividades de Debate (Potencian la interacción, el descubrimiento de otros puntos de vista, la negociación del significado, la toma de posiciones y el espíritu crítico)

a. Debatir los sentimientos del protagonista y crear hipótesis sobre las causas o circunstancias que llevan al protagonista o a los personajes del poema a obrar o a expresarse de ese modo.

b. Debatir las diferencias de puntos de vista que puedan surgir respecto al contenido del poema (ideología, reacciones del protagonista y de los personajes, actitud ante las decisiones tomadas por éstos -aceptación, simpatía, rechazo, etc.-). 
c. Comparar el contenido del poema o aspectos del mismo con sucesos o comportamientos presentes en la sociedad española. Compararla a su vez con las culturas de los países de origen de los alumnos, elaborando similitudes y diferencias.

d. Reflexionar sobre las causas que suelen llevar a alguien a obrar o pensar de ese modo, tomando el poema como ejemplo. Establecer comparaciones con los alumnos y preguntarles por su experiencia (si han tenido la misma experiencia, si han obrado de la misma forma, si han sentido lo mismo que el protagonista del poema).

e. Comparar las preguntas formuladas por los estudiantes en las actividades de prelectura al autor del poema, y ver si éste ha respondido a su pregunta a través del texto. Debatir si el poema ha cumplido las expectativas de los alumnos así como cuáles han sido los aspectos del poema que no esperaban y les han sorprendido.

f. Mostrar acuerdo o desacuerdo con alguna de las frases presentes en el poema.

g. Debatir las acciones que tomarían los estudiantes si fueran el protagonista del poema. Si el poema no proporciona el suficiente contexto, expandir o elaborar contextos imaginarios entre los alumnos y discutir las respuestas que los alumnos tomarían ante esos contextos planteados.

h. Debatir las implicaciones futuras que el pensamiento o acción del protagonista pueden tener en sí mismo y en los otros personajes del poema, así como en las circunstancias que les rodean.

i. Debatir lo que ocurre y lo que pudiera haber ocurrido en ausencia o presencia de determinados elementos en la historia.

j. Debatir las circunstancias que pudo vivir el poeta como autor para llevarle a escribir ese poema, de acuerdo con el análisis o investigación que los alumnos pudieran realizar sobre su vida y obra.

k. Buscar en Internet o preguntar (si es posible) a nativos de lengua española otras reacciones ante ese poema, y compararlas y discutirlas con las vistas en clase.

\section{CONCLUSIÓN}

En los últimos años se ha renovado el interés en la didáctica de lenguas extranjeras por el empleo de materiales literarios, entre los que la selección y 
explotación de textos poéticos ocupan un lugar muy importante. Asistimos por tanto a una progresiva reacción pendular que pasó del estudio de la lengua a través de la literatura (método de gramática y traducción) a la exclusión absoluta de ésta, para a continuación volver a recuperar con las sucesivas actualizaciones del enfoque comunicativo la utilidad y pertinencia de este tipo de textos en el aula de LE.

No obstante, la recuperación de la poesía como recurso para la enseñanza / aprendizaje en el aula sigue chocando en numerosas ocasiones con el recelo de profesores y alumnos, que continúan viendo al poema como un texto difícil, excesivamente elaborado, artificioso y poco rentable pedagógicamente. Estas consideraciones son un reflejo de las lecciones tradicionales de literatura que tanto alumnos como profesores de LE recibieron a su vez como estudiantes en contextos de lengua materna, en los que predominaban aburridos análisis centrados en la valoración de la literariedad y en el estudio de los elementos formales de la lengua, aspecto que sigue marcando muchas veces sus creencias y sus prácticas educativas. Contra esta consideración, en este artículo se defiende que los textos poéticos ofrecen en sí mismos numerosas ventajas a partir del análisis de sus propias características, aspecto que se expone de la siguiente manera:

1. La poesía no es un producto necesariamente complejo. Se pueden encontrar magníficos ejemplos de calidad poética con una sencillez en el campo léxico, morfosintáctico y simbólicoreferencial que los hace idóneos para ser trabajados en un aula de LE.

2. La poesía suele tener una extensión corta y está contextualizada en sí misma. Es un producto que por tanto puede ofrecerse en su totalidad, y cuyo análisis puede servirse de la autoreferencia que se encuentra en este tipo de textos.

3. Es ambigua, lo que favorece la variedad de interpretaciones y con ello el intercambio de puntos de vista y de lecturas sobre un mismo texto. La poesía es por tanto un instrumento de análisis y de interpretación.

4. Es motivadora, estimula y desarrolla la imaginación y la creatividad, a la vez que incentiva a defender y negociar un significado que permanece abierto por la multiplicidad de lecturas. La poesía es un instrumento de comunicación.

5. Refleja una cultura y una forma de ver el mundo, lo que promueve el conocimiento y el contacto directo con saberes y comportamientos socioculturales (relaciones personales, tradiciones, normas, valores, convenciones sociales, usos y costumbres, vida cotidiana, estilos y modos de vida, identidad, 
etc.). La poesía es un instrumento de acercamiento cultural y de análisis intercultural.

6. Ofrece un mensaje interiorizado y fuertemente subjetivado, creado desde una perspectiva personalísima y cultural que permite la posibilidad de desarrollar habilidades y actitudes interculturales (curiosidad, empatía, comprensión, aceptación, reflexión, apertura, comparación, tolerancia) a través tanto de la interpretación del texto como del control consciente de las dimensiones cognitiva, emocional y de comportamiento que ese texto y la consiguiente didactización realizada sobre el mismo generan en el alumno.

7. Ofrece una muestra particular de expresión que hace referencia a realidades que consciente o inconscientemente pueden ser demandadas por los estudiantes. La poesía es un instrumento que responde al interés de formación de nuestros alumnos, desarrollando la competencia literaria.

8. El poema es siempre un producto social y humanístico que implica al estudiante (en su inteligencia y afectividad) y activa sus conocimientos y procedimientos internos (culturales, lingüísticos, cognitivos y estratégicos) en busca de la aprehensión literal y literaria. La poesía es un instrumento catalizador en el desarrollo de competencias y estrategias.

9. Puede ser responsable de un placer estético.

Considerado lo anterior, la explotación de textos literarios debe dejar de ser considerada como una actividad complementaria del aprendizaje de una lengua para convertirse en un recurso básico de enorme potencialidad didáctica. En este sentido, uno de los mayores problemas en el uso y explotación de textos literarios en la clase de LE se sigue encontrando en el tratamiento que tradicionalmente se ha hecho y en ocasiones se sigue haciendo de estos textos, realizado a través de prácticas importadas de las clases de lengua materna. Este tipo de tratamiento se centra en la valoración artística, en la evaluación de la comprensión, en el análisis metalingüístico-literario o en el comentario de textos, sirviéndose de actividades que numerosas veces no presentan relación con el contenido de la unidad y que además ni siquiera aparecen integradas en la dinámica docente. Ha de reconocerse no obstante que este tratamiento varía en distinto grado según la orientación metodológica en la que se inserte (bien centrada en los aspectos formales de la lengua o bien integradora de otros recursos metodológicos, con énfasis en la práctica comunicativa), y que la tendencia en el aula se orienta progresivamente a la integración de los textos en el contenido de la unidad, con vistas a trabajar las competencias cultural, literaria, lingüística y comunicativa.

Junto a esto, es imprescindible tener en cuenta que el uso y explotación de textos poéticos no puede convertirse en una clase de literatura o de cómo estudiar 
literatura. En su lugar, la intención del profesor debería orientarse más bien a la que Duff y Maley sostienen en la introducción a su libro Literature (1990: 5):

The primary aim of our approach is quite simply to use literary texts as a resource (and it will not be the only resource) for stimulating language activities. This enables us to cut away the dead weight of critical commentary, metalanguage, and explanation which has historically been associated with work on literary texts.

Siguiendo a los autores, la respuesta metodológica que aquí se defiende propone adaptarse a las características y necesidades del estudiante de LE, utilizando precisamente la potencialidad presente en estos textos como recurso para la práctica comunicativa, el análisis intercultural o la interacción y defensa de la posición interpretativa y creativa. Estos textos deben considerarse además como muestra estética de expresión y de usos lingüísticos, sin entrar en valoraciones al uso que los consideren como modelos perfectos de lengua en sí mismos. Una muestra que es válida, distinta y necesaria frente otros textos no poéticos ni literarios trabajados en clase.

En función de este ideario, a lo largo de este artículo se ha defendido:

- Trabajar lengua con literatura, no literatura.

- Contribuir a la comprensión del texto, no pedirla ni dirigir las actividades hacia la comprensión como único objetivo.

- Servirse de preguntas abiertas y comunicativas, no cerradas y dirigidas.

- No aprender la lengua del texto, sino fundamentalmente en el proceso que va hacia el texto y desde el texto, a través de actividades previas y posteriores al mismo. En definitiva: utilizar un texto -en este caso un poema- como reclamo para poner en juego técnicas y actividades preparatorias que estimulen y faciliten su recepción (en forma y contenido), permitiendo la práctica y el aprendizaje, y que a su vez sirva como pretexto para hacer actividades provocadas tras su lectura, desde la creatividad y la interpretación, atendiendo a los mismos objetivos.

- Respetar lo máximo posible la integridad y propiedad del texto, "sirviéndose de él" para el aprendizaje y el posible deleite estético.

- Fomentar el desarrollo de la competencia lecto-literaria como parte integrante del proceso de aprendizaje de una LE, y no como complemento al mismo.

En este sentido, es necesario que el profesor sea un mediador que facilite el encuentro del texto con el alumno, que pueda desarrollar y servirse del texto como pretexto con fines lingüísticos, culturales y comunicativos, y que, como señala 
Mendoza Fillola (1998: 40) ayude a la formulación de propuestas de interpretación por parte del alumno "en lugar de que sea el profesor quien directamente explique $y$ dé interpretaciones". No hay que olvidarse que toda lectura es un proceso de interacción entre texto y lector (Iser, 1976), en el que el profesor puede convertirse en un magnífico guía y mediador que se sirva de las posibilidades didácticas que este proceso conlleva.

A su vez, es preciso tener en cuenta que la explotación de textos poéticos no sirve sin una adecuada selección que atienda a criterios lingüísticos, literarios, didácticos y/o temáticos. Siguiendo esta premisa, en este artículo se ha defendido que una buena selección de textos debe:

- Considerar el interés que éstos pueden producir en los alumnos.

- Garantizar que los planos morfo-sintácticos, léxico-semánticos y referenciales que integran el poema sean suficientemente accesibles a los estudiantes.

- Aprovechar las potencialidades de explotación didáctica que ofrece el texto, aplicando técnicas y recursos apropiados.

- Servirse de su contenido, estilo, adecuación temática o recursos literarios y lingüísticos, siempre y cuando estos textos tengan algo que transmitir a nuestros estudiantes y éstos puedan promover su participación activa en las actividades que se propongan sobre ellos. En este punto debe huirse de análisis reduccionistas de tipo exclusivamente lingüístico para dar también cabida a otros análisis más amplios y variados.

- Considerar un diseño de explotación didáctica flexible, creativo y abierto, y no predeterminado ni monopolizado por el profesor, con margen para reorientar, suprimir o introducir actividades sobre la marcha a partir de la reacción que el texto y la dinámica vaya produciendo en los estudiantes.

- Aprovechar la multiplicidad de lecturas que genera el texto, dando protagonismo a los estudiantes para que defiendan sus interpretaciones e interaccionen entre ellos.

- Utilizar textos poéticos originales y auténticos, no adaptados.

- Considerar poemas que ofrezcan referentes actuales, interculturales o universales reconocibles por los estudiantes.

- Huir de análisis académicos heredados de la L1, dispuestos en forma de comentarios al uso, preguntas dirigidas exclusivamente a la evaluación de la comprensión, o estudios metalingüísticos o metaliterarios que condicionan desde su inicio la recepción del texto.

- Fomentar actividades centradas en el alumno, verdaderamente comunicativas, que estimulen de forma efectiva la recepción y el interés por el texto, que faciliten el placer estético que quizás se 
encuentre en su lectura, y que lo utilicen también como pretexto, considerando sus posibilidades interpretativas.

Finalmente, es preciso considerar que unas buenas actividades de explotación de textos literarios deben cuidar especialmente tanto la fase previa a la lectura como la posterior a la lectura, de modo que permitan a los estudiantes anticipar, identificar, contextualizar, asociar, relacionar, comprender, integrar, valorar e interpretar. Y es que tradicionalmente el proceso de explotación y recepción de textos se ha reducido, a veces de modo absoluto, a la comprensión limitada de los mismos, sin tener en cuenta los múltiples y necesarios tratamientos alternativos que lo rodean (Mendoza Fillola, 1998:34). Siguiendo esta línea, en este artículo se han expuesto y explicado tres grandes tipos de actividades:

Actividades previas a la lectura:

- actividades de predicción

- actividades de contextualización

Actividades durante la lectura

Actividades posteriores a la lectura:

- actividades de expansión

- actividades de transformación

- actividades de relación

- actividades de reducción

- actividades de sustitución

- actividades de debate

Cierra el artículo la didactización y explotación del poema "La malcasada", de Luis Alberto de Cuenca, como ejemplo práctico que recoge la teoría explicada. 


\section{REFERENCIAS BIBLIOGRÁFICAS}

ACQUARONI, Rosana (2007): Las palabras que no se lleva el viento, Madrid: Santillana.

ACQUARONI, Rosana (2000): «Del texto apropiado a la apropiación del texto»: El tratamiento de la comprensión lectora en la enseñanza-aprendizaje de E/LE según las principales orientaciones metodológicas», en El desarrollo de la comprensión lectora en el aula de E/LE, Carabela, 48, Madrid: SGEL, pp.4563.

ACQUARONI, Rosana (1997): «La experiencia de la poesía (o cómo llenar de columpios la clase de gramática)», en Frecuencia L, 4, pp.17-20.

AGUIAR E SILVA, V.M.D. (1980): Competencia lingüistica y competencia literaria, Madrid, Gredos.

ALBALADEJO GARCÍA, María Dolores (2007): «Cómo llevar la literatura al aula de ELE: de la teoría a la práctica», marcoELE, revista de didáctica ELE, 5.

BALLESTER BIELSA, María del Pilar (2000): «Actividades de prelectura: Activación y construcción del conocimiento previo», en El desarrollo de la comprensión lectora en el aula de E/LE, Carabela, 48, Madrid: SGEL, pp.6583.

CASSANY, Daniel (1998): «Los procesos de escritura en el aula de E/LE», Carabela, 46, pp. 5-22.

COLLIE, Joanne y Stephen SLATER (2002): Literature in the Language Classroom: A resource book of ideas and activities. Cambridge: CUP.

ECO, Umberto (1992): Interpretation and overinterpretation. Cambridge: CUP.

FERRER PLAZA, Carlos (2009): «Poesía en la clase de ELE: Propuestas didáctica», en $V$ Encuentro brasileño de profesores de español, Suplementos marcoELE, 9.

GARRIDO, Antonio y Salvador MONTESA (1991): «La literatura en la enseñanza del español para extranjeros», en Actas de las III Jornadas Internacionales del español como lengua extranjera, Madrid: Ministerio de Cultura, pp.73-83.

ISER, Wolfang (1976): The Act of Reading: A Theory of Aesthetic Response. Baltimore: John Hopkins University Press. Trad. El acto de leer. Madrid: Taurus, 1987.

JUAREZ MORENA, Pablo (1998): «La enseñanza de la literatura en los cursos de lengua y civilización para extranjeros», en Lengua y cultura en la enseñanza del español a extranjeros, Actas del VII Congreso de ASELE, Cuenca: Ediciones de la Universidad de Castilla La Mancha, pp 277-283.

JURADO MORALES, José y Francisco ZAYAS MARTINEZ (2002): La Literatura en la Enseñanza del Español como Lengua Extranjera. Cádiz: Servicio de Publicaciones de la Universidad de Cádiz.

LAZAR, Gillian (1993): Literature and Language Teaching, Cambridge: CUP. 
MALEY, Alan y Alan DUFF (1990): Literature. Oxford: Oxford University Press. MALEY, Alan y Alan DUFF (1989): The inward Ear. Poetry in the language classroom. Cambridge: CUP. Cambridge Handbooks for language teachers.

MARTÍN PERIS, Ernesto (2000): «Textos literarios y manuales en la enseñanza del español como lengua extranjera», Lenguaje y Textos, 16, pp. 101-131.

MENDOZA FILLOLA, Antonio (2007): Materiales literarios en el aprendizaje de la lengua extranjera, Barcelona: Horsori.

MENDOZA FILLOLA, Antonio (2004): «Los materiales literarios en la enseñanza de ELE: funciones y proyección comunicativa», redELE, 1 .

MENDOZA FILLOLA, Antonio (2003): «La utilización de materiales literarios en la enseñanza de lenguas extranjeras», en Lenguas para abrir camino. Aulas de verano, Instituto Superior de Formación del Profesorado, Madrid: Secretaría General Técnica: Subdirección General de Información y Publicaciones, Ministerio de Educación, Cultura y Deporte, pp.113-166.

MENDOZA FILLOLA, Antonio (1998): Tú, lector: aspectos de la interacción texto-lector en el proceso de lectura, Barcelona: Octaedro.

MONTESA, Salvador y Antonio GARRIDO (1994): «La literatura en la clase de lengua», en Actas del II Congreso ASELE, Málaga: Servicio de Publicaciones de la Universidad de Málaga.

NARANJO, María (1999): La poesía como instrumento didáctico en la clase de $E / L E$, Madrid: Edinumen.

PRADO ARAGONES, Josefina (2004): Didáctica de la lengua y la literatura para educar en el siglo XXI, Madrid: La Muralla.

QUINTANA PAREJA, Emilio (1993): «Lengua y cultura en la clase de E/LE: la España del siglo XX a través de la poesía», en II Jornadas sobre aspectos de la enseñanza de E/LE, Universidad de Granada.

ROMERO BLAZQUEZ, Covadonga (1998): «El comentario de textos literarios: aplicación en el aula de E/LE», en Actas del VII Congreso de ASELE, lengua y cultura en la enseñanza de E/LE, ed. Universidad de Castilla La Mancha.

SANZ PASTOR, Marta (2006): «Didáctica de la literatura: el contexto en el texto y el texto en el contexto», Carabela, 59, pp. 5-23.

SELL, Jonathan P.A. (2005): "Why teach literature in the Foreign Language Classroom?», Encuentro, 15, Revista de investigación e innovación en la clase de lenguas.

STEMBERT, Rudolf (1999): «Propuestas didácticas de los textos literarios en la clase de E/LE», Expolingua. Disponible también en Monográficos marcoELE, 9.

UBACH MEDINA, Antonio (1997): «La literatura contemporánea en la clase de español», en Actas del VIII Congreso Internacional de ASELE, La enseñanza de ELE: del pasado al futuro, Alcalá de Henares. 
WIDDOWSON, Henry G. (1985): «The teaching, learning and study of literature», en Quirk, R. et ál. (eds.) English in the World, Teaching and learning the languages and literatures, Cambridge: CUP, pp. 180-196. 


\section{ANEXO}

\section{...Una actividad poética didactizada.}

\section{Antiguos amores}

a) Aquí tienes la historia del reencuentro entre dos antiguos enamorados. ¿Qué pudieron decirse? Nosotros te presentamos el texto en prosa. Además hemos suprimido las comas. Lee primero el texto y...

1) Estructura el poema en verso.

2) Marca los grupos fónicos con una raya vertical [ ]

3) Coloca los signos de puntuación (comas).

La malcasada, de Luis Alberto de Cuenca (Madrid, 1950)

Me dices que Juan Luis no te comprende que sólo piensa en sus computadoras y que no te hace caso por las noches. Me dices que tus hijos no te sirven que sólo dan problemas que se aburren de todo y que estás harta de aguantarlos. Me dices que tus padres están viejos que se han vuelto tacaños y egoístas y ya no eres su reina como antes. Me dices que has cumplido los cuarenta y que no es fácil empezar de nuevo que los únicos hombres con que tratas son colegas de Juan en IBM y no te gustan los ejecutivos. Y yo ¿qué es lo que pinto en esta historia? ¿Qué quieres que haga yo? ¿Que mate a alguien? ¿Que dé un golpe de estado libertario? Te quise como un loco. No lo niego.

b) ¿Cómo crees que continúa el texto? 


\section{$\underline{L A M A L C A S A D A}$}

Me dices que Juan Luis no te comprende, que sólo piensa en sus computadoras

y que no te hace caso por las noches.

Me dices que tus hijos no te sirven, que sólo dan problemas, que se aburren

de todo y que estás harta de aguantarlos.

Me dices que tus padres están viejos,

que se han vuelto tacaños y egoístas

y ya no eres su reina como antes. 
Me dices que has cumplido los

cuarenta

y que no es fácil empezar de nuevo,

que los únicos hombres con que tratas

son colegas de Juan en IBM

y no te gustan los ejecutivos.

Y yo, ¿qué es lo que pinto en esta historia?

¿Qué quieres que haga yo? ¿Que mate a alguien?

¿Que dé un golpe de estado libertario?

Te quise como un loco. No lo niego. 


\section{LA MALCASADA}

Luis Alberto de Cuenca (Madrid, 1950)

Me dices que Juan Luis no te comprende, que sólo piensa en sus computadoras y que no te hace caso por las noches. Me dices que tus hijos no te sirven, que sólo dan problemas, que se aburren de todo y que estás harta de aguantarlos. Me dices que tus padres están viejos, que se han vuelto tacaños y egoístas y ya no eres su reina como antes.

Me dices que has cumplido los cuarenta y que no es fácil empezar de nuevo, que los únicos hombres con que tratas son colegas de Juan en IBM y no te gustan los ejecutivos. Y yo, ¿qué es lo que pinto en esta historia? ¿Qué quieres que haga yo? ¿Que mate a alguien? ¿Que dé un golpe de estado libertario?

Te quise como un loco. No lo niego.

Pero eso fue hace mucho, cuando el mundo era una reluciente madrugada que no quisiste compartir conmigo. La nostalgia es un burdo pasatiempo. Vuelve a ser la que fuiste. Ve a un gimnasio, píntate más, alisa tus arrugas y ponte ropa sexy, no seas tonta, que a lo mejor Juan Luis vuelve a mimarte, y tus hijos se van a un campamento, $\mathrm{y}$ tus padres se mueren.

\section{El otro sueño (1987)}

Versión recitada por el autor: http://www.cervantesvirtual.com/portal/poesia/decuenca/videos.shtml 


\section{Actividades posteriores a la lectura}

1. ¿Cuál crees que es el sentimiento del poeta hacia su antigua novia? rencor / tristeza / lástima / enfado / reproche / indiferencia / despecho / amistad / amor

2. ¿Cómo crees que fue la relación entre el poeta y la protagonista de la historia? ¿Qué pudo pasarles para que siguieran vidas distintas?

3. Si fuerais el poeta... ¿qué le diríais a la protagonista?

7. Y si fuerais la protagonista... ¿qué haríais con respecto a:

1_ vuestro marido.

2_vuestro hijo.

3_ vuestros padres.

¿Cómo son para vosotros el marido / mujer, hijos y padres ideales?

¿Creéis que las quejas de ella se corresponden con lo que ocurre en la sociedad actual? ¿Por qué?

5. ¿En qué han podido cambiar con respecto al pasado las relaciones de...?:

a) Hombres y mujeres en el matrimonio

¿Por qué ahora hay más divorcios?

b) Padres e hijos

- ¿Tenéis el mismo tipo de relación que vuestros padres tenían con vuestros abuelos?

Y ahora... si fuerais padres... ¿qué relación tendríais con vuestros hijos?

- ¿Normalmente, qué ocurre en tu país cuando los padres se hacen mayores? ¿Viven solos? ¿Viven con los hijos? ¿Viven en residencias de ancianos? 


\section{Role-Play}

En este Role-Play se realiza una interpretación del poema. Se reparten los siguientes papeles (cuatro mujeres, padre y madre, dos o tres hijos, marido y poeta) entre los estudiantes y se representan en el siguiente orden:

1.

MUJER: Hace siglos que tu marido y tú no pasáis una tarde romántica fuera de casa. Vas a proponerle algo especial (decídelo), así que tendrás que pedir a tus padres que cuiden de vuestro bebé.

PADRES: Vuestra hija va a pediros algo, pero no queréis hacerlo. Inventad cualquier excusa (sois demasiado mayores para estar toda la tarde con vuestra nieta, tenéis otra cosa que hacer, etc.).

2.

MUJER: Hace siglos que tu marido y tú no pasáis una tarde romántica fuera de casa. Vas a proponerle algo especial (decídelo), así que tendrás que pedir a tus hijos mayores que cuiden de su hermano pequeño, que es un bebé.

HIJOS: Vuestra madre va a pediros algo, pero no queréis hacerlo. Inventad cualquier excusa.

3.

MUJER: A pesar de que ni tus padres ni tus hijos quieren ocuparse del bebé, hace siglos que tu marido y tú no pasáis una tarde romántica fuera de casa, y estás decidida a hacerlo. Proponle algo especial.

MARIDO: Tu mujer va a proponerte algo especial, pero tú no puedes. Inventa cualquier excusa.

4.

MUJER: Has quedado con tu antiguo novio en una cafetería. Le cuentas lo que pasa y te quejas.

POETA: Tu antigua novia quiere verte en una cafetería. Ha pasado mucho tiempo. Reacciona como en el poema o como tú quieras.

Una variante más corta de esta actividad es hacer la representación entre la mujer y el poeta únicamente. 


\section{Expresión escrita. Cambiamos el poema....}

Transforma el poema en estilo directo. Tres opciones:

Escribe las protestas que la mujer le dice al poeta.

Escribe posibles diálogos sobre una de estas cuatro situaciones:

1_ Mujer y marido;

2_ Mujer y padres;

3_Mujer e hijos;

4_Mujer y poeta.

Escribe una carta que ella le envía al poeta con sus quejas.

Escribe las respuestas que tú (como si fueras el poeta) darías a la mujer. Escríbelas en:

a) Estilo directo (imperativos, apelaciones, preguntas, etc.).*

b) Estilo indirecto (si yo fuera el poeta le diría a la chica que...) 
En parejas, ¿qué otro título pondríais al poema? Después de la puesta en común, elegid el título que os guste más, incluido el dado por Luis Alberto de Cuenca.

Cambiar los versos 1, 4 y 7 del poema y «recrear» en función de los cambios los nueve primeros versos.

Ejemplo:

Posibilidades para el verso 1

Me dices que Juan Luis es un romántico...

Me dices que Juan Luis es un tacaño...

Me dices que Juan Luis está con otra...

Para el verso 4

Me dices que tus hijos quieren ser toreros...

Para el verso 7

Me dices que tus padres van a clases de kung fu... 
Cambia el final del poema (6 últimos versos), proponiendo otro alternativo.

Cambia la historia "trágica" del poema por otra totalmente opuesta siguiendo el ejemplo: Me dices que Juan Luis te colma de atenciones.

* Esta parte puede utilizarse como continuación a la letra a o c del punto anterior. Para ello un estudiante escribe las protestas de la mujer, y otro la responde. La actividad puede mandarse de un día para otro. 


\section{ELIGE UNA DE LAS SIGUIENTES ACTIVIDADES:}

\section{AHORA TÚ ERES EL POETA...}

¡Ahora tienes la oportunidad de cambiar la historia! Escribe una «carta» que asuma en primera persona el punto de vista del poeta. Será una respuesta a las quejas que ella te ha dicho. Y tú, ¿qué le contestas? ¿Serás tan duro/a como Luis Alberto de Cuenca? ¿Le darás una oportunidad? La carta que escribas será leída en clase. Después votaremos la mejor «carta» de respuesta.

\section{LA RESPUESTA DE ELLA...}

Escribe una «carta» que asuma en primera persona el punto de vista de la mujer, escribiendo una respuesta al poeta como continuación a las palabras que éste le dice en el poema. La carta que escribas será leída en clase. Después votaremos la mejor «carta» de respuesta. 


\section{EL CONSULTORIO}

Has sido testigo de toda la historia. Escribe una «carta» a cualquiera de los personajes que aparecen en el poema (la mujer, su marido, sus hijos, sus padres, el poeta) animando, aconsejando o recriminando su comportamiento. 